\title{
Users' Perceptions on the Usage of M-commerce in Bangladesh: A SWOT Analysis
}

\author{
Md. Shafiul Alam Chowdhury ${ }^{1,}$, Md. Farukuzzaman Khan ${ }^{2}$, Md. Mahbub Alam³, \\ AHM Saifullah Sadi ${ }^{1}$, Mohammad Alauddin ${ }^{1}$ \\ ${ }^{1}$ Department of Computer Science \& Engineering, Uttara University, Dhaka, Bangladesh \\ ${ }^{2}$ Department of Computer Science \& Engineering, Islamic University, Kushtia, Bangladesh \\ ${ }^{3}$ Institute of Computer Science, Bangladesh Atomic Energy Commission, Dhaka, Bangladesh

\section{Email address:} \\ shafiul.a.chowdhury@gmail.com (Md. S. A. Chowdhury),mfkhanbd2@gmail.com (Md. F. Khan), mahbub.baec@gmail.com (Md. M. Alam), \\ saif801@yahoo.com (A. S. Sadi), alauddinsorwer@yahoo.com (M. Alauddin) \\ ${ }^{*}$ Corresponding author
}

\section{To cite this article:}

Md. Shafiul Alam Chowdhury, Md. Farukuzzaman Khan, Md. Mahbub Alam, AHM Saifullah Sadi, Mohammad Alauddin. Users' Perceptions on the Usage of M-commerce in Bangladesh: A SWOT Analysis. American Journal of Operations Management and Information Systems. Vol. 4, No. 3, 2019, pp. 87-91. doi: 10.11648/j.ajomis.20190403.13

Received: July 28, 2019; Accepted: August 27, 2019; Published: September 10, 2019

\begin{abstract}
Internet is a kind of window for business platforms commonly known as e-commerce. The term electronic commerce or e-commerce is anything that involves an online transaction. In Bangladesh big, medium even small enterprises have adopted e-business platforms, has a great potentiality to evolve e-commerce. M-commerce is a new dimension of e-commerce technology. The purpose of the research is to figure out the present scenario of m-commerce in Bangladesh to take initiative that could strengthen its future. We performed user study among local people to know their experience and opinion using it. The questionnaire were formulated based on m-commerce's strengths, weaknesses, opportunities and threats. A SWOT analysis were conducted to find realistic outcome that could be applicable to strengthen the m-commerce in Bangladesh. The secondary data is collected from Wikipedia, Ministry of Bangladesh government. The survey was conducted in different cities (Dhaka, Khulna, Rajshahi, Chittagong, Barishal, Sylhet and Rangpur) in Bangladesh. Discussions were taken place for the betterment of m-commerce as per response received from the survey and SWOT analysis result. In order to receive more realistic result the survey could be extended to more cities and local participants with different analysis method for comparison with SWOT analysis.
\end{abstract}

Keywords: User Study, M-commerce, SWOT Analysis, E-business

\section{Introduction}

Mobile Commerce often referred to as "M-Commerce" or "m-Commerce" is an extension of e-Commerce that is performed by mobile devices and PDA using mobile phone networks. Number of mobile users increasing dramatically, so the prospect of m-commerce also increasing in developing countries like Bangladesh. The expansion of the technology and revolution of mobile communication in the rural area of Bangladesh has eventually been a motivating variable in the development of M-Commerce. In the present Business organizations, mobile commerce has been presented to account, administration, retail, and telecommunication and data innovation administrations. In these areas, M-Commerce is not just being broadly acknowledged additionally it is by and large more utilized as a well-known method for business/commerce.

\section{Literature Review}

The whole world is experiencing the major transformation in retail business and Bangladesh does not differ from the global trend; the e-commerce in Bangladesh is still a young and emerging industry but growing fast [1]. The overall e-commerce websites and business to consumer category of Bangladesh (B2C) slowly expanding [2]. As compared to developed countries, fruitfulness of e-commerce is stronger in developing countries [3]. 
The rapid growth of the mobile phone users and mobile applications over the year mobile has become a vital part of human life. With the rise of mobile user, mobile commerce gets the highest priority to do business using it. The use of mobile technology as a payment gateway was started in 1997. Before the end of 2008, the number of mobile subscribers was dramatically increased in Bangladesh till now unstoppable.

\subsection{Mobile Phone, Internet and PSTN Subscribers in Bangladesh}

The Figures 1, 2 and 3 represents the real data collected from Bangladesh government official website. The facts (Figures 1, 2 and 3) presents for the year 2016 [4]. 62.248 million Internet subscribers in Bangladesh during 2016 [4] mentioned in the Figure 1 from the 62.248 million mobile Internet subscribers $58.375(93.78 \%)$ million handled by internet operators. WiMAX operator has $0.104(0.17 \%)$ million subscribers and ISP + PSTN operator maintain $3.769(6.05 \%)$ million subscribers. So, mobile internet users (m-commerce) dramatically very high $(93.78 \%)$ in Bangladesh comparing to other options. So, m-commerce (mobile commerce) plays a big role for extending this technology here.

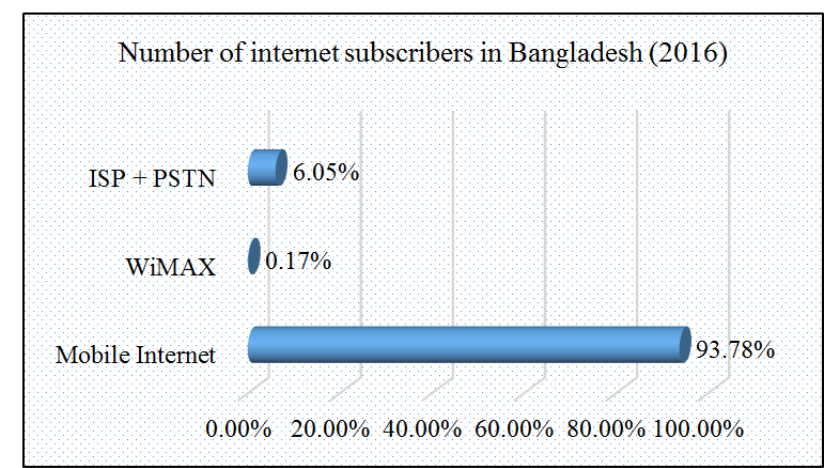

Figure 1. Number of internet subscribers in Bangladesh (2016).

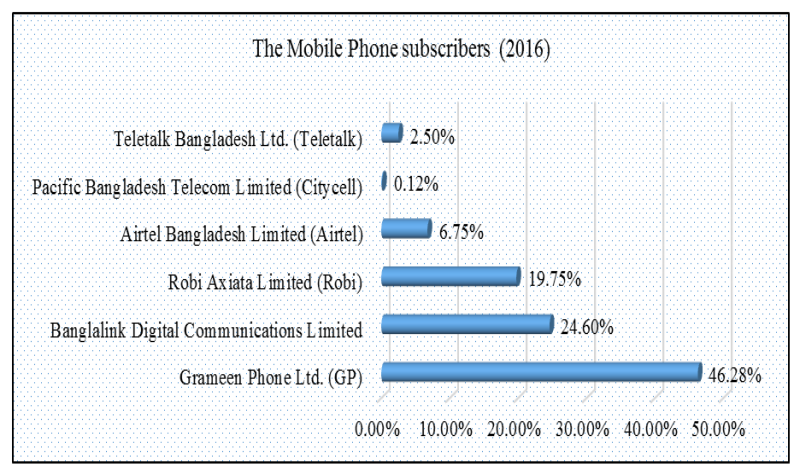

Figure 2. The Mobile Phone subscribers (2016).

Figure 2 [4] represents 117.758 million for Mobile phone subscribers in Bangladesh. Among the total, Grameen Phone Ltd. (GP) operator has 54.507 million (46.28\%) subscribers. Banglalink Digital Communications Limited operator become the second largest operator by maintaining
28.977 million (24.60\%) subscribers. Robi Axiata Limited (Robi) operator has 23.263 million (19.75\%) subscribers. for operator Airtel Bangladesh Limited (Airtel) 7.943 million (6.75\%) subscribers and for Pacific Bangladesh Telecom Limited (Citycell) operator 0.142 million (0.12\%) subscribers. Teletalk Bangladesh Ltd (Teletalk) operator has 2.925 million $(2.50 \%)$ subscribers. As an operator Grameen phone Ltd. (GP) provide services to almost half of the total mobile phone users in Bangladesh. We have seen only six operators in operations. People like Grameen phone Ltd. operator because it is the first operator in Bangladesh also the network coverage wider (almost all over the country including hill-tracks and rural areas) than other companies.

The Figure 3 [4] about 0.8095 million PSTN (public switched telephone network) subscribers at Bangladesh in 2016. Among the total-for BTCL operator 0.75 million $(92.65 \%)$ subscribers, for Ranks Telecom Ltd operator 0.0592 million (7.32\%) subscribers, for BanglaPhone Ltd operator 0.0002 million $(0.03 \%)$ subscribers. BTCL is a government company has its' own infrastructure maintaining $92.65 \%$ subscribers.

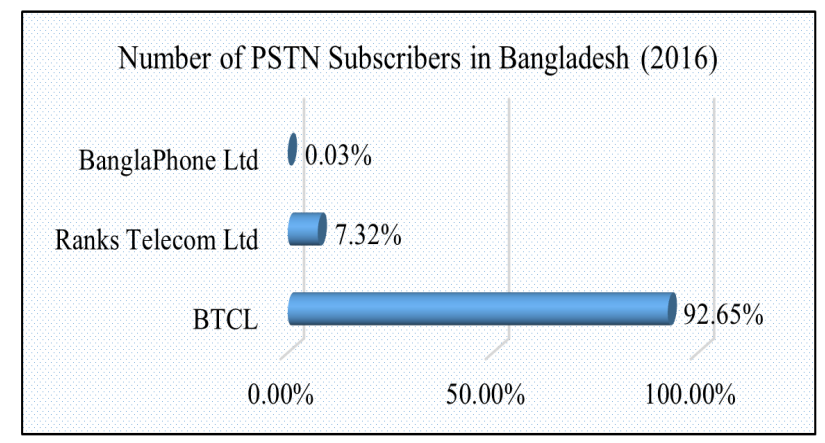

Figure 3. Number of PSTN Subscribers in Bangladesh (2016).

\subsection{Mobile Phone Subscribers Worldwide}

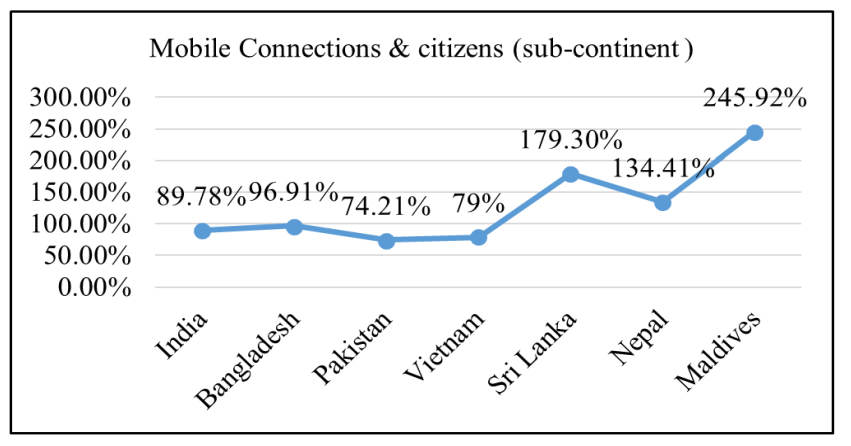

Figure 4. Mobile Connections \& citizens (sub-continent).

This list ranks the countries of the world by the number of mobile phones in use. In some countries, one person might have two mobile phones. Bangladesh ranked the number 8th [12] in the list of countries by number of mobile phones in use (subscribers) among 74 countries [6], number of mobile phones $157,048,000$ and population $162,951,000$. So, $96.91 \%$ citizens have mobile phone in Bangladesh [6]. India 89.78\% [5], Pakistan 74.21\% [7], Vietnam 79\% [8], Sri Lanka 179.3\% 
[9], Nepal 134.41\% [10] and Maldives 245.92\% [11]. Myanmar and Bhutan not considered in the ranking list.

The table 1 [5-12] and figure 4 given the real picture about the mobile phone users in the sub-continent. Bangladesh holds the 8th worldwide rank after India (2nd world rank) in this sub-continent. 96.91\% people in Bangladesh uses mobile phone which is less in percentage from Sri Lanka, Nepal and Maldives but in respect to population (Hugh population in Bangladesh and India) Bangladesh even better then India and Pakistan. For $\mathrm{m}$-commerce uses mobile user is necessary. Also we come to know why there are huge number of mobile phone internet users (93.78\%) comparing to ISP-PSTN, Wi-MAX in Bangladesh.

Table 1. List of countries by number of mobile phones in use.

\begin{tabular}{|c|c|c|c|c|}
\hline World Rank & Country & Connections/ 100 citizens & Population & Date of evaluation with reference No. \\
\hline 2 & India & $89.78 \%$ & $1,324,245,994$ & Dec $2018[5,12]$ \\
\hline 8 & Bangladesh & $96.91 \%$ & $162,951,000$ & Nov $2018[6,12]$ \\
\hline 10 & Pakistan & $74.21 \%$ & $207,774,520$ & April $2018[7,12]$ \\
\hline 18 & Vietnam & $79 \%$ & $90,549,390$ & Oct $2013[8,12]$ \\
\hline 31 & Sri Lanka & $179.30 \%$ & $21,671,000$ & Dec $2018[9,12]$ \\
\hline 33 & Nepal & $134.41 \%$ & $26,620,020$ & NTA_MIS_128, $2018[10,12]$ \\
\hline 74 & Maldives & $245.92 \%$ & 417,492 & Jul $2017[11,12]$ \\
\hline
\end{tabular}

\section{SWOT Analysis}

Using SWOT analysis for a community to organize information and provide insight into barriers [13] that may be present while engaging in social change processes, and identify strengths available that can be activated to counteract these barriers. A SWOT analysis can be used to explore new solutions to problems
[14], Identify barriers that will limit goals/objectives [14], decide on direction that will be most effective [14], reveal possibilities and limitations for change [14], revise plans to best navigate systems, communities, and organizations as a brainstorming and recording device as a means of communication [13] that can enhance credibility of interpretation to be used in presentation to leaders or key supporters [15].

\section{Table 2. SWOT Analysis}

\begin{tabular}{lll}
\hline & Helpful (To achieving the objective) & Harmful (To achieving the objective) \\
\hline Internal Origin (Attributes of the organization) & Strengths (S) & Weakness (W) \\
External Origin (Attributes of the environment) & Opportunities (O) & Threats (T) \\
\hline
\end{tabular}

\section{SWOT Analysis Based on User Study}

The number of participants in the study ware 255 and we tried to make the participation geographically wide. We distributed the questionnaire both physically and through online among the major big cities i.e., Dhaka, Khulna, Rajshahi, Chittagong, Barishal, Sylhet and Rangpur in Bangladesh. To keep our focus narrow, we avoided analysis with respect to sex, age group and profession which would produce a large number graphs and charts. Within the survey initially asked participants about how long using this technology to know their background. In SWOT analysis we try to find out the strengths and weaknesses of ecommerce in respect of Bangladeshi business environment. Then we have tried to identify opportunities and the threats from the environment. Participant's perception, experience and opinion took placed in SWOT analysis.

Figure 5 is about from how many years we are experiencing e-commerce/m-commerce in Bangladesh. Majority (40\%, 102 participants) have experience using e-commerce technology from one to five years. New user $24.70 \%$. 29.41\% has more than five years of e-commerce experience. Only $5.88 \%$ participant not much interested about this technology. So, we have seen today $94.22 \%$ participants fully aware and like to use m-commerce technology in Bangladesh. Only very few people not much interested due to lack of scopes used and education we think.

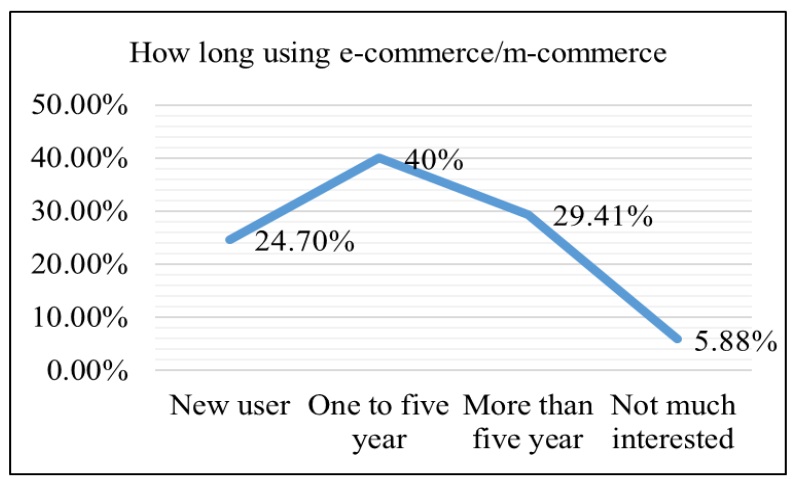

Figure 5. How long using e-commerce/m-commerce.

Figure 6 about the nine issues related to the Strengths category (SWOT analysis) of m-commerce in Bangladesh business environment. Highest (45 person) number participants given opinion about $(17.65 \%)$ World wide access (Global market). Separately $13.33 \%$ (34 person) says for both save time by reducing physical movement (Time saving) and Sharing of information among all ends very quick (Fast exchange of information). $11.37 \%$ separately (29 person) says for both Cost effective by eliminating long chain of middle man (Cost effective) and No physical movement is required to buy product (Faster buying procedure). For four issues- separately given same rank by the participants were $8.24 \%$ (21 person). i.e., Transactions can be used anywhere 
anytime (No time constraints), Price or product comparison facilities (Comparison facilities), Target market segment flexible (Flexible target market) and Almost everything can be sold even target group very small (Niche market).

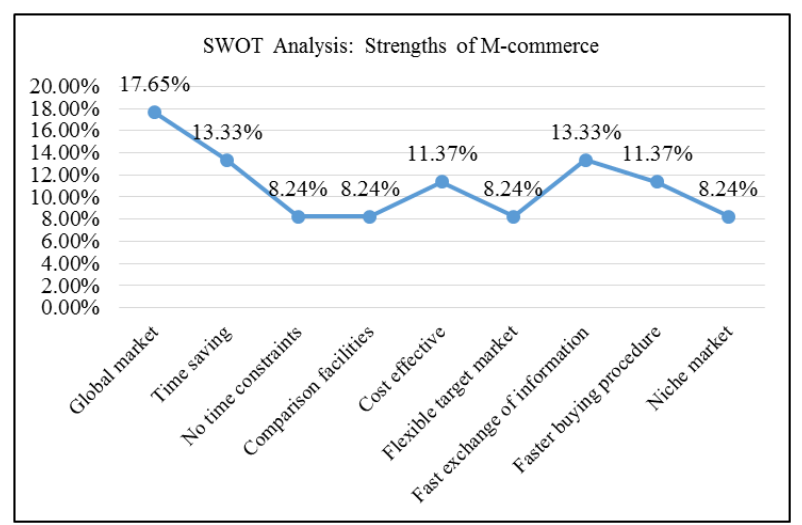

Figure 6. SWOT Analysis: Strengths of M-commerce.

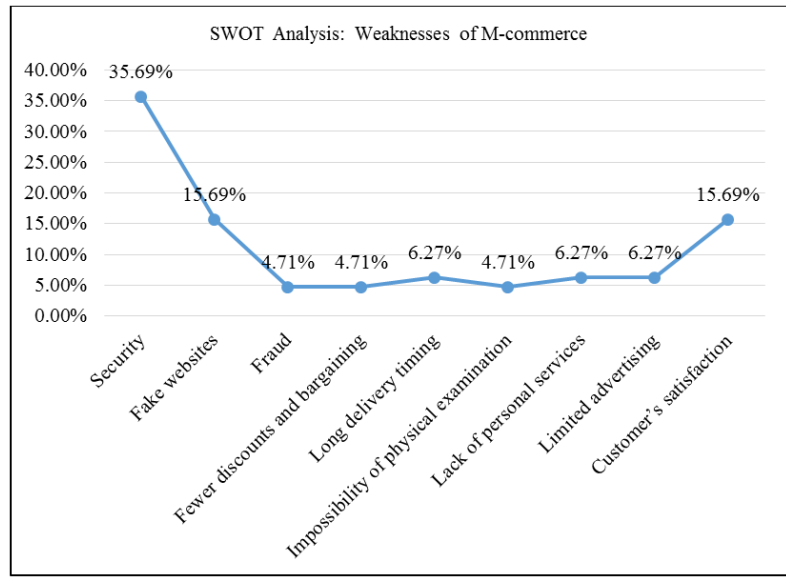

Figure 7. SWOT Analysis: Weaknesses of M-commerce.

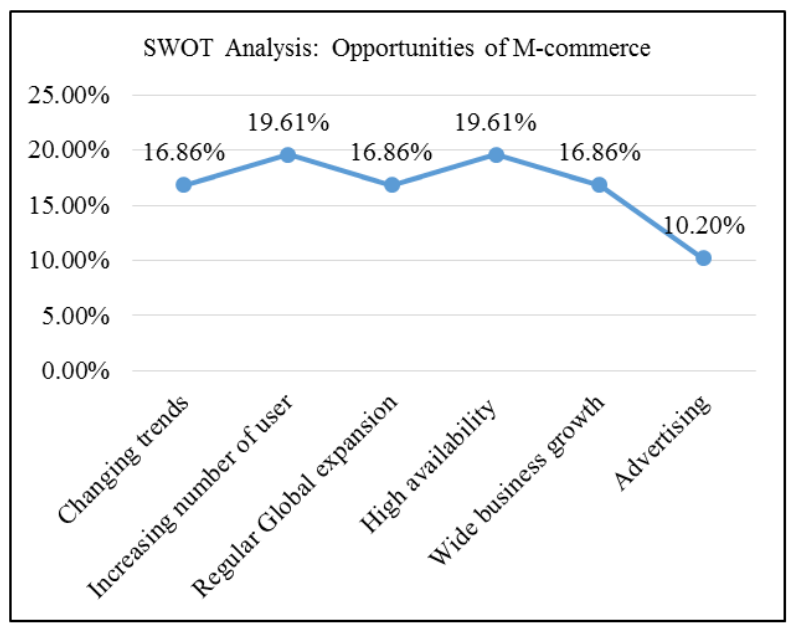

Figure 8. SWOT Analysis: Opportunities of M-commerce.

Figure 7 about the nine issues related to the Weaknesses category (SWOT analysis) of m-commerce in Bangladesh business environment. Highest (91 person) number participants gave opinion about (35.69\%) Security is a biggest challenge in to progress of $\mathrm{m}$-commerce especially payment process
(Security). For two issues separately $15.69 \%$ (40 person) said about many fake web sites disgrace and bring bad name to ecommerce (Fake websites) and No scope for convincing the customer i.e., face to face interaction between customer and the seller (Customer's satisfaction). Separately $6.27 \%$ (16 person) said for three issues i.e., outsourced delivery the seller provide their services as per their own convenience (Long delivery timing), lack in personal services which are intangible (Lack of personal services) and the advertising is limited only to computer literate person (Limited advertising). Three issues i.e., Personal and financial details provided for trading purpose are misused by hackers their personal undue interest (Fraud), Hardly online businesses offer discounts and bargaining cannot be possible. (Fewer discounts and bargaining) and Online products cannot be touched, wear or sit on the products (Impossibility of physical examination) are given separately same rank by the survey participants were $4.71 \%$ (12 person).

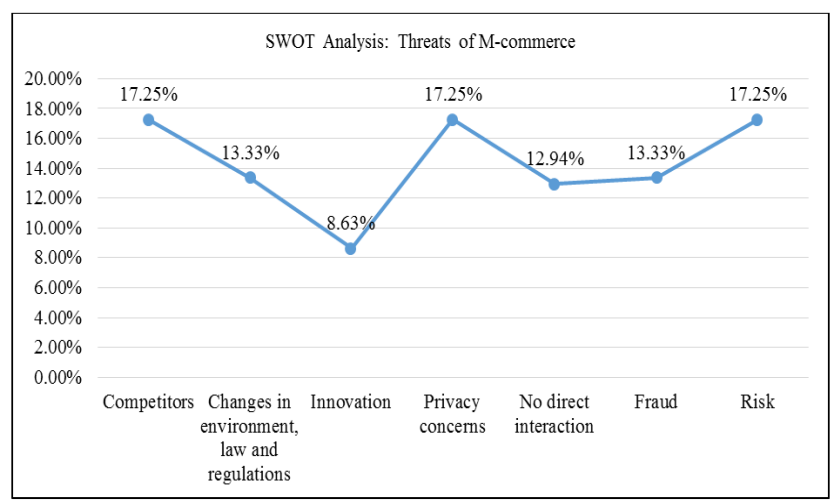

Figure 9. SWOT Analysis: Threats of M-commerce.

Figure 8 about the six issues related to the Opportunities category (SWOT analysis) of m-commerce in Bangladesh business environment. Highest (50 person) number of participants separately given opinion about (19.61\%) two issues i.e., Daily number of internet users is increasing (Increasing number of user) and the opportunity to shop as per their convenient time even during late night hour (High availability). $16.86 \%$ (43 person) separately said about three issues i.e., interested in buying branded stuff rater then local (Changing trends), E commerce/m-commerce can be operated anywhere any time without any interruption (Regular Global expansion) and E-business has wide scope and broader vision to grow (Wide business growth). $10.20 \%$ (26 person) said Advertising is cost effective as compare to conventional offline system (Advertising).

Figure 9 about the seven issues related to the Threats category (SWOT analysis) of m-commerce in Bangladesh business environment. Highest (44 person) number of participants given opinion about $(17.25 \%)$ three issues separately i.e., Big companies have already entered in this field (Competitors), Fears that information can be misused lead to spam e mail or identity fraud (Privacy concerns) and Nature of fraud (Risk). 13.33\% (34 person) separately said about two issues i.e., Change in trends, fashion and fad can distress $\mathrm{E}$ Commerce side by side change in law and 
regulations can also affect it (Changes in environment, law and regulations) and Persons using unfair means to operate ecommerce can damage the confidence and faith of common people (Fraud). 12.94\% (33 person) said There is no scope of physical interaction \& bargaining (No direct interaction). $8.63 \%$ (22 person) said about Innovation become as an extra burden for consumer to satisfy customer (Innovation).

\section{Conclusion and Discussion}

This research is an attempt to find the present scenario and future of m-commerce especially in Bangladesh. Performed user study to collect people opinion and conducted SWOT analysis to find realistic outcome which may strengthen the upcoming m-commerce in Bangladesh. 96.91\% Bangladeshi citizens have mobile phone [6]. 93.78\% mobile phone users access internet [4]. From the survey we have seen $94.22 \%$ participants directly experiencing $\mathrm{m}$-commerce accessing through internet using mobile phone.

In the SWOT analysis we have considered nine issues strengths for M-commerce in Bangladesh and asked users about these issues. These are global market, time saving, first exchange of information, cost effectiveness, faster buying procedure, no time constraints, comparison facilities, flexible target market and niche market. Proper utilizations of these issues could be strengthen the m-commerce situation as SWOT analysis says. All the participants also agreed about these issues positively strengthen and advanced the m-commerce.

We mentioned nine weakness of m-commerce and these are security issue, fake websites, customer's lack of satisfaction, long delivery timing, lack of personal services, limited advertising, frauds, fewer discounts or bargaining and impossibility of physical examination. As a solution more care and initiatives need to be taken for these issues. M-commerce provide the opportunities mentioned here areincreasing number of users, high availability, changing trends, regular global expansion, wide business growth and advertising. We have to make proper use of these opportunities. M-commerce facing threats are mentioned here- competitors, privacy concerns, risk, changes in environment - law \& regulations, unfair means to operate m-commerce, no direct interaction, and innovation. We need to find proper solution to overcome these threats. There is a very good future for m-commerce in Bangladesh if we follow the recommendation from survey based on SWOT analysis. The government and private sector plays big role for proper run and advancement of e-commerce/m-commerce in a country may consider our research and incorporate the necessary portion of it, if they want.

\section{Future Work}

We have conducted user study among 255 participants in number of cities in Bangladesh. In future the survey could be in wider range with more related issues. We have applied SWOT analysis. More tools and methods could be introduced or implemented for more appropriate solution for the related platform in future.

\section{References}

[1] Md Thohidul Karim \& Xu Qi, E-commerce Development in Bangladesh, International Business Research, Canadian Center of Science and Education, vol 11, No. 11, 2018.

[2] Md. Mohiuddin, Overview the E-Commerce in Bangladesh, IOSR Journal of Business and Management, vol 16, Issue 7, ver II, pp 01-06, July-2014.

[3] Md. Shafiqul Islam, e-Commerce in Bangladesh: Growth and Challenges, IOSR Journal of Business and Management, vol 20, Issue 3, ver 5, pp 10-15, March-2018.

[4] Government of the people's republic of Bangladesh, http://data.gov.bd/group/technology, 2016.

[5] Highlights of telecom subscription data, December-2018.

[6] Mobile phone subscribers in Bangladesh, Bangladesh Telecommunication Regulatory Commission, November-2018.

[7] Census archived from PCOPK, April-2018.

[8] IFC helps improve retail payment system in Vietnam, Vovnews. Vn., October-2013.

[9] Statistics, Trc. gov. 1k. December-2018.

[10] http://www.nta.gov.np/old/en/mis-reports-en.html, NTA MIS 128, 2018.

[11] Communications Authority of Maldives, www.cam.gov.mv, July-2017.

[12] List of countries by number of mobile phones in use, https://en.wikipedia.org/wiki/, April-2019.

[13] Chermack, Thomas J \& Bernadette K. Kasshanna, "The Use of and Misuse of SWOT analysis and implications for HRD professionals", Human Resource Development International 10 (4): 383-399, December 2007.

[14] Community Toolbox: Section 14. SWOT analysis, 02-22-2014.

[15] Westhues, Anne, Jean Lafrance \& Glen Schmidt, "A SWOT analysis of social work education in Canada", Social Work Education: The International Journal. 20 (1): 35-56, 2001. 